\title{
Phenolic compounds, organic acids profiles and antioxidative properties of beefsteak fungus (Fistulina hepatica)
}

\author{
Bárbara Ribeiro ${ }^{\text {a }}$, Patrícia Valentão ${ }^{a}$, Paula Baptista ${ }^{\text {b }}$ \\ Rosa M. Seabra a, Paula B. Andrade ${ }^{\text {a,* }}$ \\ a REQUIMTE/Serviço de Farmacognosia, Faculdade de Farmácia, Universidade do Porto, R. Aníbal Cunha, 164, 4050-047 Porto, Portugal \\ b CIMOIESAB, Quinta de Sta Apolónia, Apartado 1172, 5301-855 Bragança, Portugal
}

Received 17 March 2006; accepted 26 March 2007

\begin{abstract}
The phenolic compounds and the organic acids composition of the edible beefsteak fungus Fistulina hepatica was determined by HPLC/DAD and HPLC/UV, respectively. The results showed a profile composed by five phenolic compounds (caffeic, $p$-coumaric and ellagic acids, hyperoside and quercetin) and six organic acids (oxalic, aconitic, citric, malic, ascorbic and fumaric acids). The quantification of the identified compounds revealed that ellagic acid (ca. 49.7\%) and malic acid (ca. 57.9\%) are the main compounds in this species. In a general way the phenolic profile revealed to be more constant than the organic acids one and could be more useful for the quality control of the species. Beefsteak fungus was also investigated for its capacity to act as a scavenger of DPPH' radical and reactive oxygen species (superoxide radical, hydroxyl radical and hypochlorous acid). Good results were obtained against DPPH in a concentration-dependent manner. Beefsteak fungus also displayed good activity against superoxide radical, achieved by its capacity to act as both scavenger and xanthine oxidase inhibitor. A prooxidant effect was noticed for hydroxyl radical, which may be due to its capacity for iron ions reduction. Little ability for iron chelation was also observed. Beefsteak fungus showed a weak protective effect against hypochlorous acid.
\end{abstract}

(c) 2007 Elsevier Ltd. All rights reserved.

Keywords: Fistulina hepatica; Beefsteak fungus; Phenolic compounds; Organic acids; Antioxidant potential

\section{Introduction}

Fistulina hepatica mushroom, commonly known as beefsteak fungus, usually is a saprobic and sometimes a parasitic fungus that lives on the wood of hardwoods (especially oaks and chestnut), growing alone or in small groups near the bases of trees and on stumps, during Summer and Autumn. Its fruit body is annual, bracket-like to tongue-shaped, laterally attached. The cap diameter ranges $7-20 \times 10-20 \mathrm{~cm}$ and $2-5 \mathrm{~cm}$ thick. The upper surface is rough, salmon or orange-red to vinaceous red or rusty brown, often slimy-viscid, occasionally with moisture dripping from the margin. The tubes measure 5-10 $\mathrm{mm}$ long

\footnotetext{
* Corresponding author. Tel.: +351 222078935; fax: +351 222003977.

E-mail address: pandrade@ff.up.pt (P.B. Andrade).
}

and are whitish cream. The pores are circular, whitish to yellowish, often with guttation drops. Its flesh is juicy, soft, white-yellow to orange-red or wine red. It has a pleasant smell and the taste is somewhat sour or acidic (Keizer, 1998). As the common name suggests, beefsteak fungus is remarkably similar in appearance to raw meat. In the past, it was often cooked and eaten as a substitute for meat. It is sold in several markets and can be eaten raw in salad or with a sauce of parsley and garlic.

Despite its high consumption, there is little information about beefsteak fungus nutritional value. Previous works with this species concerned its antibiotic activity (Bianco Coletto, 1981), the characterization of acetylenic compounds (Tsuge et al., 1999; Barley et al., 1987; Farrell et al., 1973), the determination of major volatile compounds (Wu et al., 2005), chlorogenic acid (Paris et al., 
1960), amino acids (Casalicchio et al., 1975) and arabitol (Frerejacque, 1939) and of polysaccharides biological activity (Nano et al., 2002).

Phenolic compounds and organic acids are known to influence the organoleptic properties of food matrices, namely fruits and vegetables (Vaughan and Geissler, 1997) and have also been used for their quality control (Valentão et al., 1999, 2005a,b). Additionally, these compounds may be involved in the protection against various diseases, due to their antioxidant potential (Silva et al., 2004). In fact, there is an increasing amount of evidence showing that the consumption of fruits and vegetables is beneficial to health, due to the protection provided by the antioxidant phytonutrients contained in them (Pulido et al., 2000). Antioxidants are of great interest because they may help to protect the organism against reactive oxygen species (ROS). The oxidation induced by ROS can result in cell membrane disintegration, membrane protein damage and DNA mutation, which can further initiate or propagate the development of many diseases, such as cancer, liver injury and cardiovascular disease (Liao and Yin, 2000). So, nowadays consumers are aware of the need for a constant supply of phytochemicals to get the most complete antioxidant support for disease prevention, through overlapping or complementary effects (Chu et al., 2002). As far as we know, in what concerns the existence of phenolic compounds, only the identification of chlorogenic acid by paper chromatography has been referred (Paris et al., 1960) and nothing has been reported about organic acids composition or about the antioxidant capacity of the beefsteak fungus.

Because of its weather conditions and flora diversity Trás-os-Montes (northeast of Portugal) is one of the European regions with the biggest mycological patrimony of wild-mushrooms of considerable gastronomic relevance. Beyond the gastronomic importance, wild-mushrooms also have a great economical value in this region and its harvest constitutes a way of subsistence for the local residents.

Thus, the aim of the present work was to study the chemical composition of $F$. hepatica mushrooms collected in Trás-os-Montes region, relatively to phenolic compounds and organic acids, and to evaluate its antioxidant potential. In order to define the phenolics and organic acids profiles, we carried out an HPLC/diode array (HPLC/ DAD) and HPLC/UV analysis, respectively. The antioxidant activity was accessed by DPPH radical and reactive oxygen species (superoxide radical, hydroxyl radical and hypochlorous acid) scavenging assays.

\section{Materials and methods}

\subsection{Standards and reagents}

Oxalic, citric, malic, shikimic and fumaric acids were purchased from Sigma (St. Louis, MO, USA). Aconitic, caffeic, $p$-coumaric and ellagic acids, hyperoside and quercetin were from Extrasynthése (Genay, France). Methanol, formic and ascorbic acids were obtained from Merck (Darmstadt, Germany) and sulphuric acid from Pronalab (Lisboa, Por- tugal). The water was treated in a Milli-Q water purification system (Millipore, Bedford, MA, USA). DPPH, xanthine, xanthine oxidase (XO) grade I from buttermilk (EC 1.1.3.22), $\beta$-nicotinamide adenine dinucleotide (NADH), phenazine methosulfate (PMS), nitroblue tetrazolium chloride (NBT), ferric chloride anhydrous $\left(\mathrm{FeCl}_{3}\right)$, ethylenediaminetetraacetic acid disodium salt (EDTA), trichloroacetic acid, thiobarbituric acid, deoxyribose, sodium hypochlorite solution with $4 \%$ available chlorine $(\mathrm{NaOCl}), 5,5^{\prime}$-dithiobis(2-nitrobenzoic acid) (DTNB) were obtained from Sigma Chemical Co. (St. Louis, USA).

\subsection{Samples}

Samples of $F$. hepatica were collected at different plots from the same chestnut orchard (Castanea sativa Mill.) in Bragança region (Trás-osMontes, Portugal), in 2004 . Samples 1 and 3 were collected in September at plots 2 and 4, respectively. Sample 2 was collected in October at plot 3 of the same orchard. Each sample represents a mixture of three individual mushrooms.

After harvesting, the mushrooms were immediately transferred to the laboratory and dried at $30^{\circ} \mathrm{C}$ for seven days, until constant weight. Taxonomic identification was made according to several authors (Bas et al., 1990-2001; Bon, 1988; Courtecuisse and Duhem, 1995; Courtecuisse, 1999; Marchand, 1971-1986; Moser, 1983) and representative voucher specimens were deposited at the herbarium of "Escola Superior Agrária of Instituto Politécnico de Bragança”.

\subsection{Extraction of phenolics and organic acids}

For the chemical characterization and antioxidant activity assays an aqueous extract was prepared: $10 \mathrm{~g}$ of powdered mushroom $(910 \mu \mathrm{m})$ were boiled for $30 \mathrm{~min}$ in $500 \mathrm{~mL}$ of water and then filtered over a Büchner funnel. The resulting extract was lyophilized in a Labconco 4.5 Freezone apparatus (Kansas City, MO, USA). The lyophilized extracts were kept in an exsicator, in the dark. For phenolic compounds and organic acids analysis the lyophilized extract was redissolved in water and in sulphuric acid $0.01 \mathrm{~N}$, respectively. Sample 3 was used to check the antioxidant capacity of beefsteak fungus.

\subsection{HPLC analysis of organic acids}

The separation of the organic acids was carried out as previously reported (Ferreres et al., 2005), in a system consisting of an analytical HPLC unit (Gilson) in conjunction with a column heating device set at $30^{\circ} \mathrm{C}$, with an ion exclusion column, Nucleogel ${ }^{\circledR}$ Ion 300 OA $(300 \times 7.7 \mathrm{~mm})$. Briefly, elution was carried out isocratically with sulphuric acid $0.01 \mathrm{~N}$, at a solvent flow rate of $0.2 \mathrm{~mL} \mathrm{~min}^{-1}$. The detection was performed with an UV detector set at $214 \mathrm{~nm}$.

Organic acids quantification was achieved by the absorbance recorded in the chromatograms relative to external standards, and the peaks in the chromatograms were integrated using a default baseline construction technique.

\subsection{HPLC analysis of phenolics}

The extracts were analysed using an analytical HPLC unit (Gilson), with a Spherisorb ODS $2(25.0 \times 0.46 \mathrm{~cm} ; 5 \mu \mathrm{m}$, particle size $)$ column (Valentão et al., 2005a). The solvent system used was a mixture of waterformic acid (19:1) (A) and methanol (B). Elution was performed at a flow rate of $0.9 \mathrm{~mL} / \mathrm{min}$ and the gradient was as follows: $5 \% \mathrm{~B}$ at $0 \mathrm{~min}, 15 \% \mathrm{~B}$ at $3 \mathrm{~min}, 25 \% \mathrm{~B}$ at $13 \mathrm{~min}, 30 \% \mathrm{~B}$ at $25 \mathrm{~min}, 35 \% \mathrm{~B}$ at $35 \mathrm{~min}, 45 \% \mathrm{~B}$ at $39 \mathrm{~min}, 45 \% \mathrm{~B}$ at $42 \mathrm{~min}, 50 \% \mathrm{~B}$ at $44 \mathrm{~min}, 55 \% \mathrm{~B}$ at $47 \mathrm{~min}, 70 \% \mathrm{~B}$ at $50 \mathrm{~min}, 75 \% \mathrm{~B}$ at $56 \mathrm{~min}$, and $80 \% \mathrm{~B}$ at $60 \mathrm{~min}$. Detection was achieved with a Gilson diode array detector. The compounds in each sample were identified by comparing their retention times and UV-vis spectra in the 200-400 nm range with the library of spectra previously compiled by the authors. Peak purity was checked by means of the Gilson 160 SpectraViewer Software Contrast Facilities. 
Phenolic compounds quantification was achieved by the absorbance recorded in the chromatograms relative to external standards, at $250 \mathrm{~nm}$ for ellagic acid, at $320 \mathrm{~nm}$ for caffeic and p-coumaric acids and at $350 \mathrm{~nm}$ for hyperoside and quercetin. The peaks in the chromatograms were integrated using a default baseline construction technique.

\subsection{DPPH' scavenging activity}

The antiradical activity of the extracts was determined spectrophotometrically in an ELX808 IU Ultra Microplate Reader (Bio-Tek Instruments, Inc), by monitoring the disappearance of $\mathrm{DPPH}^{-}$at $515 \mathrm{~nm}$, according to a described procedure (Silva et al., 2004). The reaction mixtures in each well consisted of $25 \mu \mathrm{l}$ aqueous extract and $200 \mu \mathrm{l}$ of $150 \mathrm{mM}$ DPPH. The plate was incubated for $40 \mathrm{~min}$ at room temperature after addition of DPPH. Three experiments were performed in triplicate.

\subsection{Evaluation of superoxide radical scavenging activity}

Antiradical activity was determined spectrophotometrically in an ELX808 IU Ultra Microplate Reader (Bio-Tek Instruments, Inc.) in a kinetic function, by monitoring the effect of the lyophilized extract on the superoxide radical-induced reduction of NBT, at $562 \mathrm{~nm}$.

\subsubsection{Non-enzymatic assay}

Superoxide radicals were generated by the NADH/PMS system according to a described procedure (Valentão et al., 2001). PMS is reduced by NADH and superoxide radical is formed after reaction with oxygen:

$\mathrm{NADH}+\mathrm{H}^{+}+\mathrm{PMS} \rightarrow \mathrm{NAD}^{+}+\mathrm{PMSH}_{2}$

$\mathrm{PMSH}_{2}+2 \mathrm{O}_{2} \rightarrow \mathrm{PMS}+2 \mathrm{O}_{2}^{--}+2 \mathrm{H}^{+}$

The reaction mixtures in the sample wells consisted of NADH $(166 \mu \mathrm{M})$, NBT $(43 \mu \mathrm{M})$, lyophilized extract and PMS $(2.7 \mu \mathrm{M})$, in a final volume of $300 \mu$ l. All components were dissolved in phosphate buffer $(19 \mathrm{mM}, \mathrm{pH}$ 7.4). The assays were performed at room temperature during 2 min and started with the addition of PMS. Three experiments were performed in triplicate. volume of $300 \mu$ l. Xanthine was dissolved in $\mathrm{NaOH}(1 \mu \mathrm{M})$ and subsequently in phosphate buffer $50 \mathrm{mM}$ with EDTA $(0.1 \mathrm{mM}, \mathrm{pH} 7.8)$, xanthine oxidase in EDTA $0.1 \mathrm{mM}$ and the other components in phosphate buffer $50 \mathrm{mM}$ with EDTA $(0.1 \mathrm{mM}, \mathrm{pH} 7.8)$. The assays were performed at room temperature during $2 \mathrm{~min}$ and started with the addition of XO. Three experiments were performed in triplicate.

\subsubsection{Effect on xanthine oxidase activity}

The effect of the lyophilized extract on xanthine oxidase activity was evaluated by measuring the formation of uric acid from xanthine in a double beam spectrophotometer (He $\lambda$ ios $\alpha$, Unicam), at room temperature, according to a described procedure (Valentão et al., 2001). The reaction mixtures contained the same proportion of components as in the enzymatic assay for superoxide radical scavenging activity, except NBT, in a final volume of $600 \mu \mathrm{l}$. The absorbance was measured at $295 \mathrm{~nm}$ for $2 \mathrm{~min}$ and started with the addition of xanthine oxidase. Three experiments were performed in triplicate.

\subsection{Hydroxyl radical assay}

The deoxyribose method for determining the scavenging effect of the aqueous extract on hydroxyl radicals was performed as described before (Valentão et al., 2002) in a double beam spectrophotometer (He $\lambda$ ios $\alpha$, Unicam), programmed in photometric function, with the wavelength fixed at $532 \mathrm{~nm}$.

Hydroxyl radical is generated in a Fenton system, according to:

$$
\mathrm{Fe}^{2+}-\mathrm{EDTA}+\mathrm{H}_{2} \mathrm{O}_{2} \rightarrow \mathrm{Fe}^{3+}-\mathrm{EDTA}+\mathrm{OH}^{-}+\mathrm{HO}
$$

Ascorbic acid accelerates hydroxyl radical formation by reducing $\mathrm{Fe}^{3+}$ ions to $\mathrm{Fe}^{2+}$ :

\section{$\mathrm{Fe}^{3+}-$ EDTA + ascorbic acid $\rightarrow \mathrm{Fe}^{2+}-$ EDTA + dehydro-ascorbic acid}

Hydroxyl radical is detected by its ability to degrade deoxyribose into fragments. The heating of the mixture under acid conditions leads to the formation malonaldehyde. This is detected by its reaction with thiobarbituric acid, with the formation a pink chromogen:<smiles>CCCC=O</smiles>

\subsubsection{Enzymatic assay}

Superoxide radicals were generated by the xanthine/xanthine oxidase (X/XO) system following a described procedure (Valentão et al., 2001). Xanthine oxidase catalyzes the oxidation of xanthine to uric acid, with superoxide radical formation:
Reaction mixtures contained, in a final volume of $1 \mathrm{ml}, 50 \mu \mathrm{M}$ ascorbic acid, $40 \mu \mathrm{M} \mathrm{FeCl}_{3}, 2 \mathrm{mM}$ EDTA, $2.8 \mathrm{mM} \mathrm{H}_{2} \mathrm{O}_{2}, 2.8 \mathrm{mM}$ deoxyribose, lyophilized extract and $10 \mathrm{mM} \mathrm{KH}_{2} \mathrm{PO}_{4}-\mathrm{KOH}$ buffer ( $\mathrm{pH}$ 7.4) as solvent. This assay was also performed either in the absence of ascorbic acid or EDTA, in order to evaluate the extract's prooxidant ability and its metal<smiles>O=c1[nH]c(=O)c2[nH]c(=O)[nH]c2[nH]1</smiles>

The reaction mixtures in the sample wells consisted of xanthine $(44 \mu \mathrm{M}), \mathrm{XO}(0.29 \mathrm{U} / \mathrm{ml}), \mathrm{NBT}(50 \mu \mathrm{M})$, and lyophilized extract, in a final chelation potential, respectively. Three experiments were performed in triplicate. 


\subsection{Hypochlorous acid scavenging activity}

The inhibition of hypochlorous acid-induced 5-thio-2-nitrobenzoic acid (TNB) oxidation to 5,5'-dithiobis(2-nitrobenzoic acid) was performed according to a described procedure (Valentão et al., 2002), in a double beam spectrophotometer (He $\lambda$ ios $\alpha$, Unicam).

For the assay, $75 \mu \mathrm{M} \mathrm{HOCl}$ was prepared immediately before use by adjusting a solution of $\mathrm{NaOCl}$ to $\mathrm{pH} 6.2$ with diluted sulfuric acid. The concentration of $\mathrm{HOCl}$ was further determined spectrophotometrically at $235 \mathrm{~nm}$ using the molar absorption coefficient of $100 \mathrm{M}^{-1} \mathrm{~cm}^{-1}$.

TNB was also prepared immediately before use. Briefly, to a $1 \mathrm{mM}$ solution of DTNB in a $50 \mathrm{mM}$ potassium phosphate buffer $(\mathrm{pH}$ 6.6) containing $5 \mathrm{mM}$ EDTA, $20 \mathrm{mM}$, sodium borohydride was added. The solution was incubated at $37^{\circ} \mathrm{C}$ for $30 \mathrm{~min}$. The concentration of TNB was determined by measuring the absorbance at $412 \mathrm{~nm}$ and using the molar absorption coefficient of $13,600 \mathrm{M}^{-1} \mathrm{~cm}^{-1}$.

The assay was performed at room temperature in a cuvette containing $78.6 \mu \mathrm{M}$ TNB, with or without the lyophilized extract. The absorbance was measured at $412 \mathrm{~nm}$, before and $5 \mathrm{~min}$ after the addition of $\mathrm{HOCl}(60 \mu \mathrm{M})$. Scavenging of hypochlorous acid was ascertained by using lipoic acid as a reference scavenger. Three experiments were performed in triplicate.

\section{Results and discussion}

The high consumption of edible wild-growing mushrooms demands a better knowledge of their chemical composition and biological potential. So, this work was developed in order to identify and quantify the phenolic compounds and organic acids of the beefsteak fungus ( $F$. hepatica) and to evaluate its antioxidant capacity.

\subsection{Phenolic compounds}

Data from phenolic compounds in edible mushrooms is scarce. The analysis by HPLC/DAD of the aqueous extract of beefsteak fungus revealed the existence of several phenolic acids and flavonoids: caffeic acid, p-coumaric acid, hyperoside, ellagic acid and quercetin (Fig. 1). All these compounds are reported for the first time in F. hepatica.
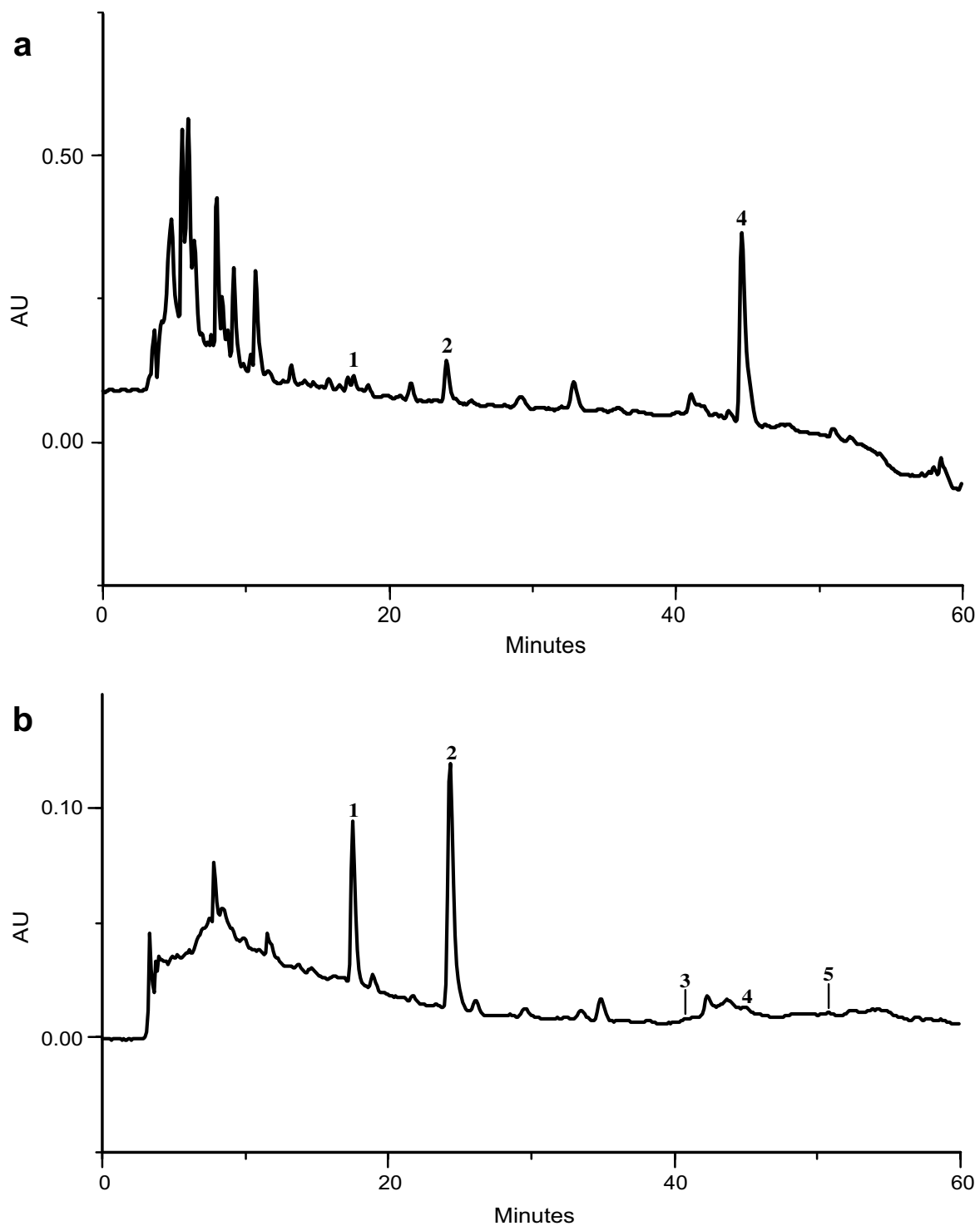

Fig. 1. HPLC phenolic profile of Fistulina hepatica. Detection at (a) 250 and (b) $320 \mathrm{~nm}$ : (1) caffeic acid; (2) p-coumaric acid; (3) hyperoside; (4) ellagic acid and (5) quercetin. 
Caffeic and $p$-coumaric acids were described before in other mushroom species (Valentão et al., 2005a; Matilla et al., 2001). Chlorogenic acid, which was previously reported to occur in this species (Paris et al., 1960), was not found in the analysed samples.

Data from the quantification of the identified compounds showed that the phenolics amounts in beefsteak fungus ranged from ca. 367 to $549 \mathrm{mg} / \mathrm{kg}$ (Table 1). The phenolic profile obtained revealed that ellagic acid was the main compound, representing ca. $49.7 \%$ of total identified compounds. Caffeic and $p$-coumaric acids were present in similar relative contents, corresponding to ca. $24.0 \%$ and $26.7 \%$ of total phenolics. Hyperoside and quercetin were detected only in trace amounts in the lyophilized extracts (Table 1).

When comparing these results with those obtained for Cantharellus cibarius (Valentão et al., 2005a), another edi-

Table 1

Phenolic compounds content in Fistulina hepatica samples $(\mathrm{mg} / \mathrm{kg}$, dry basis) $)^{\mathrm{a}}$

\begin{tabular}{|c|c|c|c|c|c|c|}
\hline \multirow[t]{3}{*}{ Compound } & \multicolumn{6}{|c|}{ Samples } \\
\hline & \multicolumn{2}{|l|}{1} & \multicolumn{2}{|l|}{2} & \multicolumn{2}{|l|}{3} \\
\hline & Mean & SD & Mean & SD & Mean & SD \\
\hline Caffeic acid (RT $17.3 \mathrm{~min}$ ) & 101.0 & 0.9 & 99.0 & 1.8 & 139.7 & 2.1 \\
\hline$p$-Coumaric acid (RT $24.6 \mathrm{~min})$ & 94.8 & 2.0 & 162.3 & 3.6 & 124.5 & 4.3 \\
\hline Hyperoside (RT $41.0 \mathrm{~min}$ ) & $\mathrm{nq}$ & & $\mathrm{nq}$ & & $\mathrm{nq}$ & \\
\hline Ellagic acid (RT $44.5 \mathrm{~min}$ ) & 171.1 & 4.1 & 257.8 & 3.3 & 284.6 & 0.0 \\
\hline Quercetin (RT $51.1 \mathrm{~min}$ ) & $\mathrm{nq}$ & & $\mathrm{nq}$ & & $\mathrm{nq}$ & \\
\hline$\sum$ & 366.9 & & 519.0 & & 548.8 & \\
\hline
\end{tabular}

nq: not quantified.

${ }^{a}$ Results are expressed as mean of three determinations. SD: standard deviation; $\sum$ : sum of the determined phenolic compounds. ble species highly appreciated in Europe, it can be seen that beefsteak fungus exhibit a higher phenolics content. From the comparison with Agaricus bisporus and Lentinus edodes (Matilla et al., 2001), it can be noticed that caffeic acid content is higher in beefsteak fungus.

\subsection{Organic acids}

The HPLC/UV analysis allowed the identification of six organic acids in beefsteak fungus: oxalic, aconitic, citric, malic, ascorbic and fumaric acids (Fig. 2). These compounds are reported for the first time in $F$. hepatica. All of them have already been described in other edible wildmushrooms species (Valentão et al., 2005a,b), with the exception of aconitic acid.

The quantification of the identified compounds revealed that beefsteak fungus exhibits high organic acids content, in which malic acid is the main compound, representing ca. $57.9 \%$ of total acids (Table 2). Malic acid was already the main organic acid in other studied wild-mushrooms species (Valentão et al., 2005a,b). Some differences were noticed in the relative contents of citric and ascorbic acid: in samples 2 and 3 citric acid corresponded to $7.9 \%$ of total acids, while in sample 1 it represented ca. $20.0 \%$ of total compounds. On the other hand, sample 2 showed the highest ascorbic acid relative amount (ca. $34.5 \%$ of total acids), which corresponded to ca. 12.1 and $19.8 \%$ in samples 1 and 3 , respectively (Table 2 ). Thus, it seems that the organic acids profile is less constant than the phenolic compounds one. Oxalic and aconitic acids were the compounds present in lowest amounts (Table 2). In a general way, and despite the different plots of origin, the results obtained suggest that samples collected in September (samples 1 and 3)

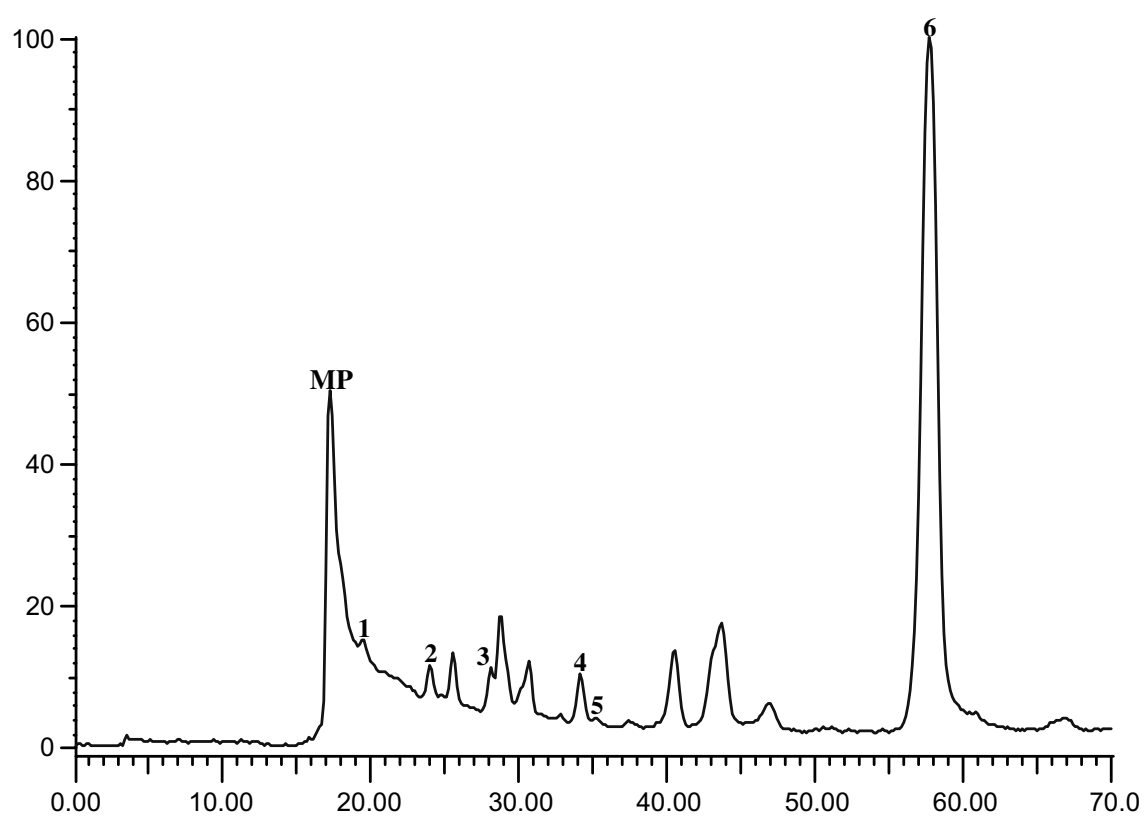

Fig. 2. HPLC organic acid profile of Fistulina hepatica. Detection at 214 nm: (MP) mobile phase; (1) oxalic acid; (2) cis-aconitic acid; (3) citric acid; (4) malic acid; (5) ascorbic acid and (6) fumaric acid. 
Table 2

Organic acids content in Fistulina hepatica samples (mg/kg, dry basis) ${ }^{\mathrm{a}}$

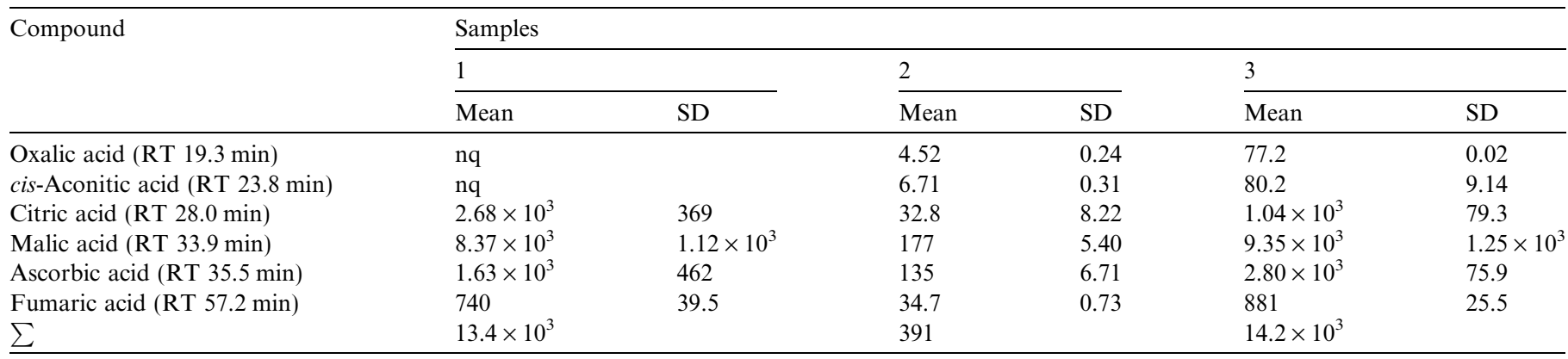

nq: not quantified.

${ }^{\text {a }}$ Results are expressed as mean of three determinations. SD: standard deviation; $\sum$ : sum of the determined organic acids.

exhibit higher organic acids contents than that one collected in October (sample 2) (ca. 13,790 and $391 \mathrm{mg} / \mathrm{kg}$, respectively).

\subsection{Antioxidant activity}

ROS produced in vivo include superoxide radical, hydrogen peroxide and hypochlorous acid. Hydrogen peroxide and superoxide can interact in the presence of certain transition metal ions to yield a highly-reactive oxidizing species, the hydroxyl radical (Aruoma et al., 1989). The DPPH' assay provides basic information on the antiradical activity of extracts. In the present work the lyophilised aqueous extract of beefsteak fungus displayed an effective antioxidant capacity, in a concentration-dependent manner, with an $\mathrm{IC}_{25}$ at $136 \mu \mathrm{g} \mathrm{mL}^{-1}$ (Fig. 3).

Superoxide radical scavenging activity was determined spectrophotometrically by monitoring the effect of beefsteak fungus lyophilized extract on the reduction of NBT to the blue chromogen formazan. Beefsteak fungus lyophilized extract revealed to be a potent scavenger of superoxide radical generated in the $\mathrm{X} / \mathrm{XO}$ system, and the effect was concentration-dependent $\left(\mathrm{IC}_{50}\right.$ at $\left.114 \mu \mathrm{g} \mathrm{mL}^{-1}\right)$ (Fig. 4). Taking into account that an inhibitory effect on the enzyme itself would also lead to a decrease in NBT reduction (Valentão et al., 2001), the effect of the lyophi-

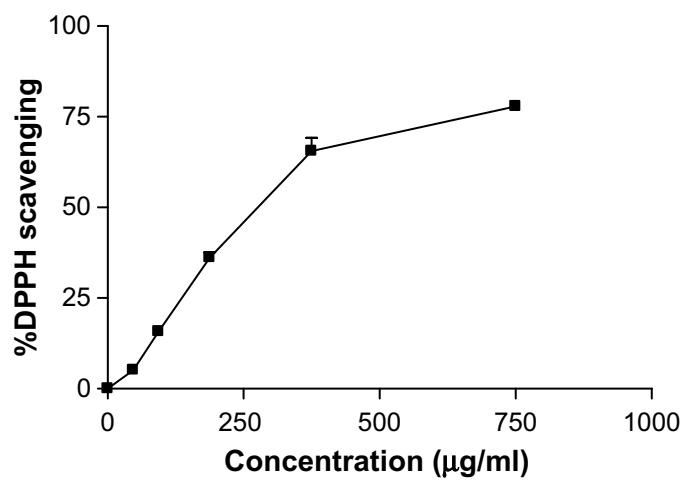

Fig. 3. Effect of the mushroom Fistulina hepatica on DPPH reduction. Values show mean $\pm \mathrm{SE}$ from 3 experiments performed in triplicate.

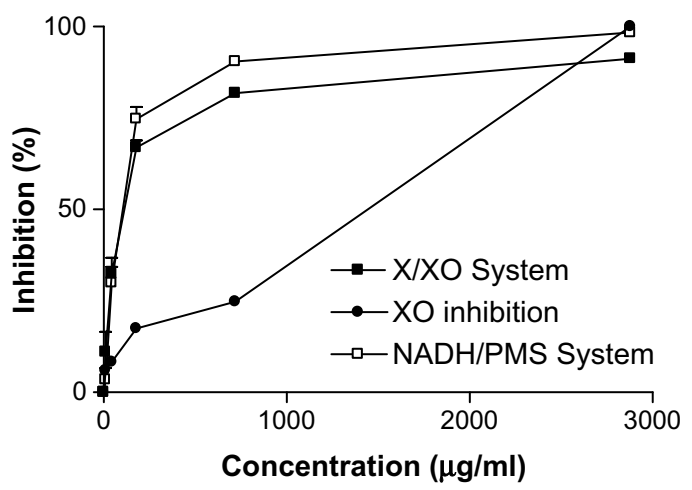

Fig. 4. Effect of the mushroom Fistulina hepatica on NBT reduction induced by superoxide radical generated in an $\mathrm{X} / \mathrm{XO}$ system, on $\mathrm{XO}$ activity and on NBT reduction induced by superoxide radical generated in a NADH/PMS system. Values show mean \pm SE from 3 experiments performed in triplicate.

lised extract on the metabolic conversion of xanthine to uric acid was studied. The results demonstrate that the beefsteak fungus exerted some inhibitory effect on $\mathrm{XO}$, which was concentration dependent $\left(\mathrm{IC}_{50}\right.$ at $\left.1444 \mu \mathrm{g} \mathrm{mL}^{-1}\right)$ (Fig. 4). Therefore, it was not possible to show a clearcut scavenging effect on superoxide radical. The capacity of the lyophilized extract to strongly scavenge superoxide radicals in a concentration-dependent way was confirmed when this radical was generated by a chemical system, composed by PMS and $\mathrm{NADH}$, and an $\mathrm{IC}_{50}$ at $105 \mu \mathrm{g} \mathrm{mL}$ was found (Fig. 4). So, beefsteak fungus lyophilized extract exhibits antioxidant activity, achieved by its capacity to act as both superoxide radical scavenger and $\mathrm{XO}$ inhibitor.

Hydroxyl radicals are produced by Fenton-type reactions, in which transition metals (e.g., iron) reduce hydrogen peroxide. Reducing agents such as ascorbic acid can accelerate hydroxyl radical formation by reducing $\mathrm{Fe}^{3+}$ ions to $\mathrm{Fe}^{2+}$ (Puppo, 1992). Hydroxyl radical can be detected by its ability to degrade the sugar deoxyribose into fragments ( $\mathrm{Li}$ and Xie, 2000). The heating of the resultant mixture under acid conditions leads to the formation malonaldehyde, which is detected by its ability to react with thiobarbituric acid forming a pink chromogen 


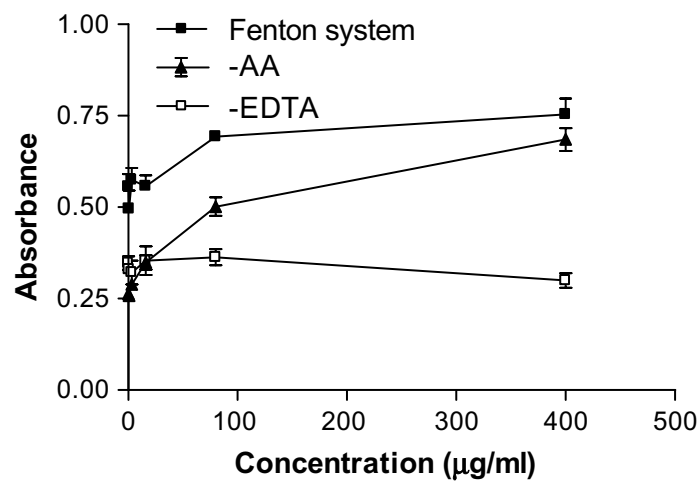

Fig. 5. Mushroom Fistulina hepatica non-specific hydroxyl radical scavenging activity, prooxidant activity (-AA) and specific hydroxyl radical scavenging (-EDTA). Values show mean $\pm \mathrm{SE}$ from 3 experiments performed in triplicate.

(Halliwell et al., 1987). In the present work the lyophilised extract of beefsteak fungus increased the oxidation of deoxyribose, in a concentration-dependent way, suggesting a prooxidant effect (Fig. 5).

If we omit ascorbate in the reaction mixture, and if prooxidant compounds with ability to reduce the metal ion required for hydroxyl generation are present, they will promote generation of hydroxyl radicals and an increase of deoxyribose degradation will be observed (Puppo, 1992). In order to evaluate the prooxidant potential of the lyophilized extract we omitted ascorbic acid in the assay and a prooxidant effect was confirmed at the tested concentrations (Fig. 5). Thus, the prooxidant behaviour exhibited by beefsteak fungus in the deoxyribose assay might be due to its capacity to reduce iron ions, as it was observed when hydroxyl radicals were generated in the absence of ascorbic acid.

The assay performed in the absence of EDTA provides information not only on the ability of a scavenger to react with hydroxyl radical, but also on its ability to form complexes with iron ions (Halliwell et al., 1987). Beefsteak fungus lyophilised extract showed little capacity to chelate iron ions for concentrations above $400 \mu \mathrm{g} \mathrm{mL} \mathrm{m}^{-1}$ (Fig. 5).

The oxidizing capacity of $\mathrm{HOCl}$ induces the oxidation of TNB $\left(\lambda_{\max }=412 \mathrm{~nm}\right)$ into DTNB $\left(\lambda_{\max }=325 \mathrm{~nm}\right)$. The presence of a $\mathrm{HOCl}$ scavenger inhibits the $\mathrm{HOCl}$-induced TNB oxidation. Under the assayed conditions, lipoic acid was used as a reference compound and inhibited TNB oxidation in a concentration-dependent manner $\left(\mathrm{IC}_{25}\right.$ at $21 \mu \mathrm{M}$ ) (Fig. 6a). Beefsteak fungus lyophilized extract exhibited a weak antioxidant protective activity against damage by $\mathrm{HOCl}$, with an $\mathrm{IC}_{15}$ at $1458 \mu \mathrm{g} \mathrm{mL}^{-1}$ (Fig. 6b).

When comparing the antioxidant activity of beefsteak fungus with that of other edible mushrooms species it could be noticed that in what concerns the DPPH assay, beefsteak fungus presents a better result (Cheung et al., 2003; Yang et al., 2002; Lo and Cheung, 2005; Turkoglu et al., 2007; Ferreira et al., 2007). Despite the good activity exhibited against superoxide radical, this is a little inferior to
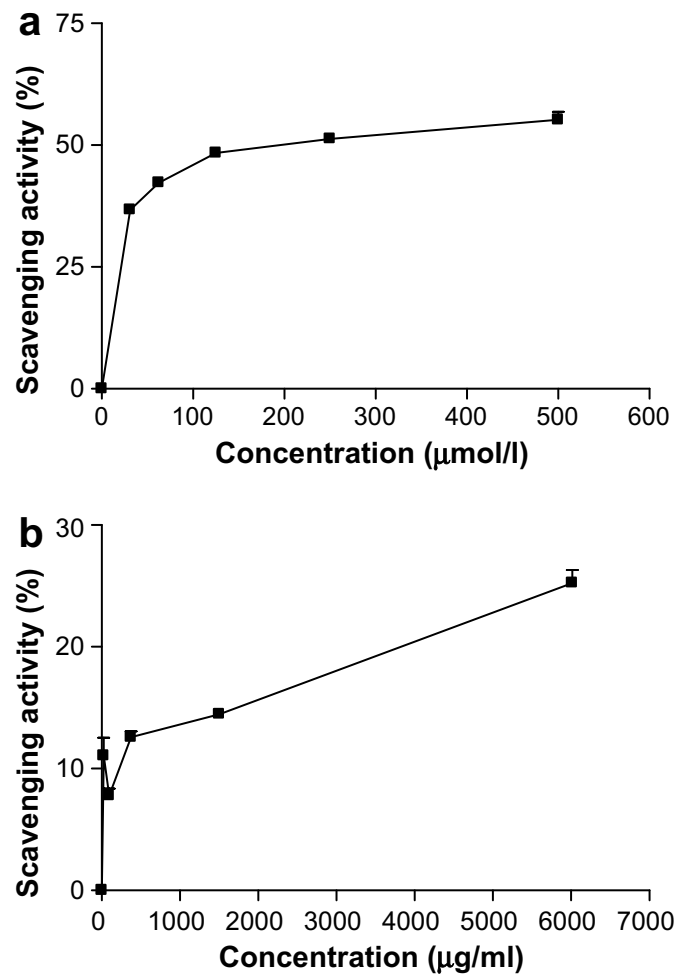

Fig. 6. Effect of (a) lipoic acid and (b) Fistulina hepatica on the oxidation of TNB by $\mathrm{HOCl}$. The amount of TNB unchanged after incubation is calculated and expressed as percentage of the initial value. Values show mean $\pm \mathrm{SE}$ from 3 experiments performed in triplicate.

that observed forMorchella vulgaris and M. esculenta (Aboul-Enein et al., in press). However, this species showed no protective effect against hydroxyl radical, being distinct from other mushrooms (Yang et al., 2002). In addition, its chelating effect on iron ions is lower than that registered for winter, shiitake and oyster mushrooms (Yang et al., 2002).

The activity exhibited by beefsteak fungus lyophilized extract is the resulting sum effect of the several compounds present, belonging to different chemical classes. Certainly, the phenolic compounds and the organic acids of the extract should contribute to the antioxidant capacity to an important extent. In fact, the antioxidant capacity of caffeic, $p$-coumaric and ellagic acids in several models is well known (Meyer et al., 1998; Yu et al., 2005; Fukumoto and Mazza, 2000; Moran et al., 1997), such as that of the organic acids (Silva et al., 2004; Kayashima and Katayama, 2002). However, also the prooxidant activity of these compounds has been reported (Fukumoto and Mazza, 2000; Yamanaka et al., 1997; Galati et al., 2002; Paolini et al., 1999), which can partially explain the prooxidant effect observed in the deoxyribose assay. In addition, the ascorbic acid content presented by the tested sample (ca. $20 \%$ ), could be a factor contributing to the prooxidant activity exhibited by beefsteak fungus.

In conclusion, the results obtained in this study indicate that beefsteak fungus may constitute an easily accessible source of natural antioxidants, namely phenolic 
compounds and organic acids. This species can be used as a possible food supplement or as antioxidative agent in the food industry, but some care should be taken because of the pro-oxidative effect observed.

Additionally, in a general way the phenolic profile revealed to be more constant than the organic acids one. These results are very promising but the phenolics composition of more beefsteak fungus samples from other geographical origins should be analysed in order to prove whether these metabolites may be useful markers of these mushrooms.

\section{Acknowledgement}

Bárbara Ribeiro is indebted to Fundação para a Ciência e a Tecnologia for a grant (SFRH/BD/22108/2005).

\section{References}

Aboul-Enein, H.Y., Elmastas, M., Turkekul, I., Öztürk, L., Gülçin, I., Isildak, O., in press. Antioxidant activity of two wild edible mushrooms Morchella vulgaris and Morchella esculenta from north Turkey. Fitoterapia.

Aruoma, O.I., Halliwell, B., Hoey, B.M., Butler, J., 1989. The antioxidant action of $\mathrm{N}$-acetylcysteine: its reaction with hydrogen peroxide, hydroxyl radical, superoxide, and hypochlorous acid. Free Radic. Biol. Med. 6, 593-597.

Barley, G.C., Graf, U., Higham, C.A., Cathryn, A., Jarrah, M.Y., Jones, E.R.H., 1987. Natural acetylenes. Part 61. Fungal Polyacetylenes and the crepenynate pathway: the biosynthesis of some C9-C14 polyacetylenes in fungal cultures. J. Chem. Res. Synop. 7, 232-233.

Bas, C., Kuyper, T.H.W., Noordeloos, M.E. and Vellinga, E.C., 19902001. In: Flora Agaricina Neerlandica: Critical monographs on families of agarics and boleti occurring in the Netherlands, vol. 1-5, A.A Balkema, Rotterdam.

Bianco Coletto, M.A., 1981. Basidiomycetes in relation to antibiosis. II. Antibiotic activity of mycelia and culture liquids. G. Batteriol. Virol. Immunol. 74, 7-12.

Bon, M., 1988. In: Guia de campo de los hongos de Europa, Ediciones Ómega, Barcelona.

Casalicchio, G., Paoletti, C., Bernicchia, A., Govi, G., 1975. Research on the amino acid composition of some fungi. Micologia Italiana 4, 2132.

Cheung, L.M., Cheung, P.C.K., Ooi, V.E.C., 2003. Antioxidant activity and total phenolics of edible mushroom extracts. Food Chem. 81, 249255.

Chu, Y.F., Sun, J., Wu, X., Liu, R.H., 2002. Antioxidant and antiproliferative activities of common vegetables. J. Agric. Food Chem. 50, 6910-6916.

Courtecuisse, R., 1999. Mushrooms of Britain and Europe. Harper Collins Publishers, London.

Courtecuisse, R., Duhem, B., 1995. Mushrooms and Toadstools of Britain and Europe. Harper Collins Publishers, London.

Farrell, I.W., Keeping, J.W., Pellatt, M.G., Martin, G., Thaller, V., 1973. Natural acetylenes. XLI. Polyacetylenes from fungal fruiting bodies. J. Chem. Soc. Perkin Trans. 22, 2642-2643.

Ferreira, I.C.F.R., Baptista, P., Vilas-Boas, M., Barros, L., 2007. Freeradical scavenging capacity and reducing power of wild edible mushrooms from northeast Portugal: individual cap and stripe activity. Food Chem. 100, 1511-1516.

Ferreres, F., Sousa, C., Vrchovska, V., Valentão, P., Pereira, J.A., Seabra, R.M., Andrade, P.B., 2005. Chemical composition and antioxidant activity of tronchuda cabbage internal leaves. Eur. Food Res. Technol. $222,88-98$.
Frerejacque, M., 1939. Presence of D-arabitol in Fistulina hepatica. Comptes Rendus Hebdomadaire des Seances de l'Academie des Sciences 208, 1123-1124.

Fukumoto, L.R., Mazza, G., 2000. Assessing antioxidant and prooxidant activities of phenolic compounds. J. Agric. Food Chem. 48, 3597 3604.

Galati, G., Sabzevari, O., Wilson, J.X., O’Brien, P.J., 2002. Prooxidant activity and cellular effects of the phenoxyl radicals of dietary flavonoids and other polyphenolics. Toxicology 177, 91-104.

Halliwell, B., Gutteridge, M.C., Aruoma, O.I., 1987. The deoxyribose method: a simple test-tube assay for determination of rate constants for reactions of hydroxyl radicals. Anal. Biochem. 165, 215-219.

Kayashima, T., Katayama, T., 2002. Oxalic acid is available as a natural antioxidant in some systems. Biochim. Biophys. Acta 1573, 1-3.

Keizer, G.J., 1998. The Complete Encyclopaedia of Mushrooms. Rebo Publishers, Lisse, p. 134.

Li, C., Xie, B., 2000. Evaluation of the antioxidant and pro-oxidant effects of tea catechin oxypolymers. J. Agric. Food Chem. 48, 6362-6366.

Liao, K.-L., Yin, M.-C., 2000. Individual and combined antioxidant effects of seven phenolic agents in human erythrocyte membrane ghosts and phosphatidylcholine liposome systems: importance of the partition coefficient. J. Agric. Food Chem. 48, 2266-2270.

Lo, K.M., Cheung, P.C.K., 2005. Antioxidant activity of extracts from the fruiting bodies of Agrocybe aegerita var alba.. Food Chem. 89, 533539.

Marchand, A., 1971-1986. In: Champignons du Nord et du Midi, Tome 1-9, Soc. Mycol. Pyrénées Mediterranéenes, Persignan.

Matilla, P., Könkö, K., Eurola, M., Pihlava, J.-M., Astola, J., Vahteristo, L., Hietaniemi, V., Kumpulainen, J., Valtonen, M., Piironen, V., 2001. Contents of vitamins, mineral elements, and some phenolic compounds in cultivated mushrooms. J. Agric. Food Chem. 49, 2343-2348.

Meyer, A.S., Heinonen, M., Frankel, E.N., 1998. Antioxidant interactions of catechin, cyanidin, caffeic acid, quercetin, and ellagic acid on human LDL oxidation. Food Chem. 61, 71-75.

Moran, J.F., Klucas, R.V., Grayer, R.J., Abian, J., Becana, M., 1997. Complexes of iron with phenolic compounds from soybean nodules and other legume tissues: prooxidant and antioxidant properties. Free Radic. Biol. Med. 22, 861-870.

Moser, M., 1983. Keys to Agarics and Boleti (Polyporales, Boletales, Agaricales, Russulales). Roger Phillips, London.

Nano, G.M., Binello, A., Bianco, M., Ugazio, G., Burdino, S., 2002. In vitro tests to evaluate potential biological activity in natural substances. Fitoterapia 73, 140-146.

Paolini, M., Pozzetti, L., Pedulli, G.F., Marchesi, E., Cantelli-Forti, G., 1999. The nature of prooxidant activity of vitamin C. Life Sci. 64, 273 278.

Paris, R.R., Durand, M., Bonnet, J.L., 1960. Identification of chlorogenic acid in mushrooms by paper chromatography. Ann. Pharmac. Fran. 18, 769-772.

Pulido, R., Bravo, L., Saura-Calixto, F., 2000. Antioxidant activity of dietary polyphenols as determined by a modified ferric reducing/ antioxidant power assay. J. Agric. Food Chem. 48, 3396-3402.

Puppo, A., 1992. Effect of flavonoids on hydroxyl radical formation by Fenton-type reactions: influence of the iron chelator. Phytochemistry $31,85-88$.

Silva, B.M., Andrade, P.B., Valentão, P., Ferreres, F., Seabra, R.M., Ferreira, M.A., 2004. Quince (Cydonia oblonga Miller) fruit (pulp, peel, and seed) and jam: antioxidant activity. J. Agric. Food Chem. 52, 4705-4712.

Tsuge, N., Mori, T., Hamano, T., Tanaka, H., Shin-ya, K., Seto, H., 1999. Cinnatriacetins $\mathrm{A}$ and $\mathrm{B}$, new antibacterial triacetylene derivatives from the fruiting bodies of Fistulina hepatica. J. Antibiot. 52, 578-581.

Turkoglu, A., Duru, M.E., Mercan, N., Kivrak, I., Gezer, K., 2007. Antioxidant and antimicrobial activities of Laetiporus sulphureus (Bull.). Murrill. Food Chem. 101, 267-273.

Valentão, P., Areias, F., Andrade, P.B., Ferreres, F., Seabra, R.M., 1999. Analysis of vervain flavonoids by HPLC/diode-array detector. Its application to quality control. J. Agric. Food Chem. 47, 4579-4582. 
Valentão, P., Fernandes, E., Carvalho, F., Andrade, P.B., Seabra, R.M., Bastos, M.L., 2001. Antioxidant activity of Centaurium erythraea infusion evidenced by its superoxide radical scavenging and xanthine oxidase inhibitory activity. J. Agric. Food Chem. 49, 3476-3479.

Valentão, P., Fernandes, E., Carvalho, F., Andrade, P.B., Seabra, R.M., Bastos, M.L., 2002. Antioxidative properties of cardoon (Cynara cardunculus L.) infusion against superoxide radical, hydroxyl radical, and hypochlorous acid. J. Agric. Food Chem. 50, 4989-4993.

Valentão, P., Andrade, P.B., Rangel, J., Ribeiro, B., Silva, B.M., Baptista, P., Seabra, R.M., 2005a. Effect of the conservation procedure on the contents of phenolic compounds and organic acids in chanterelle (Cantharellus cibarius) mushroom. J. Agric. Food Chem. 53, 49254931.

Valentão, P., Lopes, G., Valente, M., Barbosa, P., Andrade, P.B., Silva, B.M., Baptista, P., Seabra, R.M., 2005b. Quantitation of nine organic acids in wild mushrooms. J. Agric. Food Chem. 53, 3626-3630.
Vaughan, J.G., Geissler, C.A., 1997. The New Oxford Book of Food Plants. Oxford University Press, New York, p. 196.

Wu, S., Krings, U., Zorn, H., Berger, R.G., 2005. Volatile compounds from the fruiting bodies of beefsteak fungus Fistulina hepatica (Schaeffer: Fr.) Fr. Food Chem. 92, 221-226.

Yamanaka, N., Oda, O., Nagao, S., 1997. Prooxidant activity of caffeic acid, dietary non-flavonoid phenolic acid, on $\mathrm{Cu}^{2+}$-induced low density lipoprotein oxidation. FEBS Lett. 405, 186-190.

Yang, J.-H., Lin, H.-C., Mau, J.-L., 2002. Antioxidant properties of several commercial mushrooms. Food Chem. 77, 229-235.

Yu, Y.-M., Chang, W.-C., Wu, C.-H., Chiang, S.-Y., 2005. Reduction of oxidative stress and apoptosis in hyperlipidemic rabbits by ellagic acid. J. Nutr. Biochem. 16, 675-681. 